(4) 3

2. ex in

atis

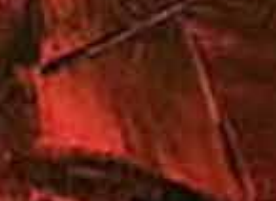

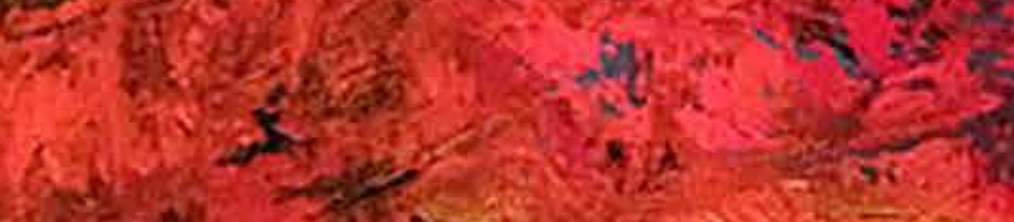

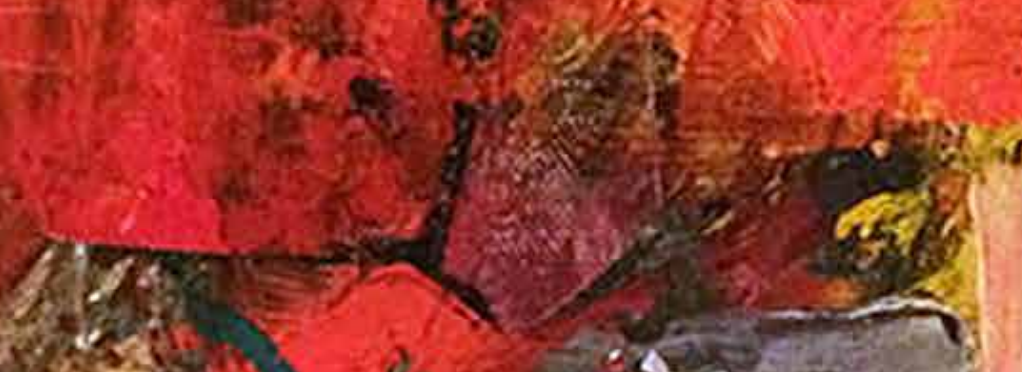

neas?

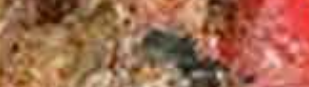
(6). at

2.

\section{(a) 19}

ath 2

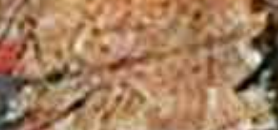

(2)

sen $\rightarrow$

2ex $x$

atis?

20.7?

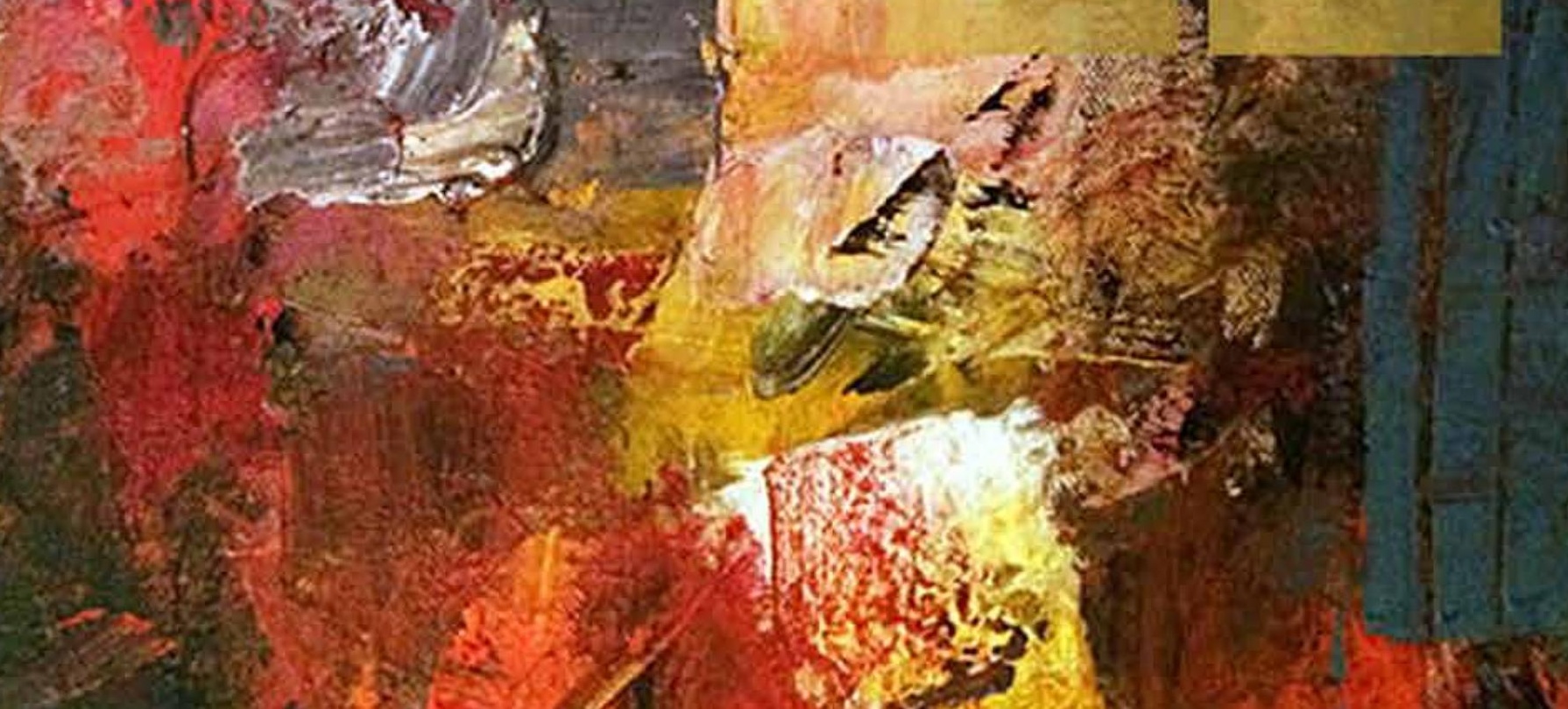

$\left\{x^{3}=2 x+\frac{x}{2}\right.$

is $x$

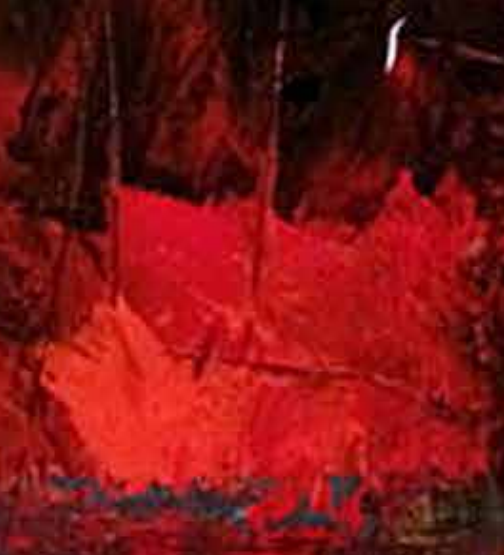




\section{Versos a los migrantes hondureños}

$$
0 \% 7
$$

Caminante, migrante, camina, que larga jornada te espera, para llegar donde imaginas, habita el sueño que anhelas.

No temas, migrante hondureño, la tierra es de Dios, no del hombre, camina en busca de tu sueño, $y$ escribe orgulloso tu nombre.

Si con Dios vas en tu caminar, nada habrá que te haga detener, así como no detuvo el mar, al pueblo guiado por Moisés.

Nunca regreses a tu pueblo con la cabeza agachada, regresa cuando puedas verlo, con luz de triunfo en la mirada.

$Y$ si a Esquipulas has de volver, aquí estrecharemos tu mano, de la misma manera que ayer, porque tú eres nuestro hermano.

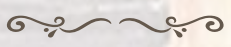

\section{Guilver Salazar}




\title{
4. Movimientos migratorios internos del Distrito Central y San Pedro Sula en Honduras, 1988-2013
}

\author{
Manuel Antonio Flores Fonseca ${ }^{1}$ \\ DOI: 10.5377/pdac.v14i0.6852 \\ Recibido: 11/04/2018 Aceptado: 02/06/2018
}

\begin{abstract}
Resumen: El estudio de la migración interna en el país ha sido relegado por la notoriedad que ha tenido la migración internacional. Los datos reflejan que en Honduras hay una tendencia al aumento en el número de migrantes internos en las últimas seis décadas, pero más recientemente a partir de la mitad de ese período hay una disminución de la proporción de migrantes. Este artículo con carácter descriptivo muestra el fenómeno migratorio interno partiendo de datos censales a nivel de División Administrativa Menor (DAME) que en este caso es el Municipio. Es de apuntar que la cuantía de la migración absoluta y reciente a nivel de DAME supera a los niveles estimados a nivel de División Administrativa Mayor Departamental (DAM), ya que cuando el nivel geográfico es más reducido hay mayores probabilidades de desplazamiento. Si hay una mayor similitud en las migraciones recientes que en las absolutas a nivel de DAM y DAME, producto de la utilización de un período de referencia más cercano a la fecha de empadronamiento. En Honduras los dos municipios de mayor atractivo migratorio, absoluta y reciente, han sido el Distrito Central y San Pedro Sula. Sin embargo, la primacía migratoria de estos dos municipios ha cambiado espectacularmente al convertirse en divisiones con saldos migratorios recientes negativos, especialmente en San Pedro Sula (municipio con el más alto saldo migratorio negativo reciente del país), y en menor medida también el Distrito Central, aunque ambos reciben y envían fuertes contingentes de migrantes entre ellos, a su vez tienen intercambios a DAME cercanas y lejanas.
\end{abstract}

Palabras clave: Migración interna de Honduras, Migración interna absoluta, Migración interna reciente, Migración interna del Distrito Central y San Pedro Sula.

\section{Internal migratory movements of the Central District and San Pedro Sula in Honduras, 1988-2013}

Summary: The study of internal migration in the country has been relegated by the notoriety that international migration has had. The data shows that in Honduras there is a tendency to increase the number of internal migrants in the last six decades, but more recently, from the middle of that period there is a decrease in the proportion of migrants. This research with a descriptive character, studies the internal migration phenomenon based on census data at the level of the Minor Administrative Division, which in this case is the Municipality. It should be noted that the amount of absolute and recent migration at the DAME (Municipality) level exceeds the levels estimated at the DAM (Department) level, the geographic level is lower there are greater chances of displacement. If there is a greater similarity in recent migrations than in absolute migrations at the level of DAM and DAME, product of the use of a reference period closer to the date of enumeration. In Honduras, the two municipalities with the greatest migratory attractiveness, absolute and recent, have been the Central District and San Pedro Sula. However, the migratory primacy of these two municipalities has changed dramatically as they have become divisions with recent negative migration balances, especially in San Pedro Sula (the municipality with the highest negative recent migratory balance in the country), and to a lesser extent, the Central District, although both receive and send strong contingents of migrants among them, in turn they have exchanges with DAME near and far.

Key words: Internal migration of Honduras, Absolute internal migration, Recent internal migration, Internal migration of the Central District and San Pedro Sula.

\section{Introducción}

La historia refleja que la migración siempre ha estado presente entre los seres humanos como actividad inherente de movilización a otras tierras, en busca de alimento, refugio de las condiciones desfavorables del clima, tierra, animales y de sus congéneres, o por la curiosidad por conocer otros entornos para aprender, comerciar, trabajar o de diversión.

Estas motivaciones también han evolucionado con el tiempo hasta la actualidad, que hace que las migraciones giren en torno a los efectos de los desastres naturales, la huida de los conflictos armados y la violencia en varias zonas del mundo. Se incluyen también los desajustes del mercado laboral principalmente en la inserción de los jóvenes.
En el caso de los movimientos internos generalmente son generados por inequidades territoriales que parten de las condiciones económicas desiguales y que repercuten en la obtención de trabajo o de generar emprendimientos que consecuentemente lleven a la obtención de ingresos, que cuando son reducidos influyen en la persistencia de la pobreza, otras desigualdades giran en torno al acceso a la educación como formas de adquisición de conocimientos y habilidades, como del acceso a la salud que permita estar cerca de la infraestructura de mejor calidad. A su vez los movimientos internos se producen en mayor medida en la juventud, en la conformación y reunificación de las familias y en algunos factores que influyen en el imaginario de las personas por vivir una vida en mejores condiciones.

1 Máster en Población y Desarrollo, Profesor de la Universidad Nacional Autónoma de Honduras, UNAH. Email: manuel.flores@unah.edu.hn, maflofo@yahoo.com 
En Honduras las desigualdades socioeconómicas siempre han existido, incluso han evolucionado a través del tiempo, desde la ubicación y conformación de cacicazgos y tribus en el territorio, como del proceso de poblamiento en la época colonial y después de la incipiente vida independiente, otros generados en la Reforma Liberal con la conformación de enclaves, minero y bananero, de los periodos de conflictos armados internos y de dictaduras, como del nacimiento del Estado moderno y de la planificación centralizada del desarrollo, la dotación de infraestructura vial, educativa y de salud, reforma agraria, introducción de las maquilas, los desastres naturales, proceso de urbanización, turismo y más recientemente con la profundización del neoliberalismo. Todos estos factores pueden haber influido en la conformación de territorios más desarrollados y otros menos desarrollados, por esa razón los desplazamientos migratorios obedecen en cierta medida a esa lógica, hay que agregar la búsqueda de oportunidades laborales y las decisiones personales y familiares y en los últimos años la proliferación de la violencia que produce desplazados que no son propiamente movimientos voluntarios.

Los desplazamientos migratorios en el país se han estudiado a nivel de División Administrativa Mayor (DAM) y División Administrativa Menor (DAME) utilizando datos censales; en ambos niveles geográfico administrativo se evidencian dos polos de atracción, uno en la parte norte (Cortés) y otro en la parte central del país (Francisco Morazán), y gravitan en torno de ellos los municipios del Valle de Sula con su epicentro en San Pedro Sula, capital industrial del país y en el centro en el Distrito Central (Tegucigalpa-Comayagüela) capital gubernamental, sede de los poderes del Estado. A partir de la introducción de la industria maquiladora en el norte del país, los municipios de Choloma y Villanueva adquirieron importancia migratoria por el flujo receptor. Más recientemente, aunque se mantiene el patrón migratorio en la migración absoluta descrito, en los movimientos recientes se producen cambios y tendencias que giran en torno a la pérdida de atractivo migratorio de San Pedro Sula y el Distrito Central.

Este artículo tiene por objetivo analizar la migración interna (absoluta y reciente) del Distrito Central en el centro de la nación (capital de la República y gran sede gubernamental), que comprende la unión de dos ciudades gemelas, Tegucigalpa y Comayagüela y forma un solo municipio denominado Distrito Central (MDC) y San Pedro Sula, ubicada en el norte (capital industrial del país). Partimos del hallazgo reciente de que la primacía de estos dos municipios que son migratoriamente atractivos ha cambiado sorpresivamente al convertirse en divisiones con saldos migratorios negativos, especialmente en San Pedro Sula (municipio con el mayor saldo migratorio negativo reciente del país), y en menor medida el Distrito Central, aunque ambos tienen un fuerte intercambio ya que reciben y envían migrantes entre ellos, y también tienen intercambios a las DAME cercanas y lejanas.

\section{Marco referencial}

El estudio de la migración interna aunque empezó en los años setenta en el país, cierto es que hasta puede considerarse incipiente, ya que aunque en los últimos años se tiene acceso virtual a las fuentes de datos demográficos para su estudio y también a tabulaciones especiales generadas con indicadores de medición, la capacidad de generación del conocimiento a través de la investigación científica no ha sido aprovechada por los estudiosos de la población y de otras áreas afines.

Los estudios migratorios de San Pedro Sula y el Distrito Central son muy pocos, aunque son los municipios de mayor desarrollo económico, concentración poblacional, urbanización y de movilidad interna e internacional, siempre se ha considerado que su atractivo migratorio es irrefutable y que ha continuado en el tiempo.

Un estudio del impacto de la industria maquiladora en la migración interna llevado a cabo por el Foro Nacional para las Migraciones de Honduras (FONAMIH) indica que está industria manufacturera se convirtió en uno de los factores que produjo las migraciones internas de las personas que en busca de trabajo se desplazaron a otras localidades en su afán de mejorar sus condiciones de vida, este fenómeno se presentó en mayor medida en las mujeres que llegaron a las ciudades maquiladoras a trabajar. Estos desplazamientos que son llamados de la "tercera etapa de movimientos internos" sucedió cuando se aceleró la implementación de incentivos para la inserción de empresas maquiladoras en la tarea del Estado por diversificar la economía y lógicamente generar empleos (Foro Nacional para las Migraciones en Honduras, 2007).

El estudio de la migración hacia el Distrito Central realizado por Sierra (2016) se enfoca en los inmigrantes internos que los caracteriza demográficamente y en sus condiciones de pobreza, encontrando niveles de desigualdad principalmente en las migrantes mujeres, que tienen baja escolaridad, condiciones de pobreza y en edades reproductivas. 
Fernández (2016) demuestra que en la relación entre migración interna y mercado laboral en San Pedro Sula hay un diferencial entre los salarios de los sectores tradicional y moderno y los desplazamientos migratorios de las personas que buscan trasladarse para mejorar, sin embargo, hay un deterioro del mercado laboral que afecta a todos, pero en mayor medida a los migrantes recientes que se convierten en precarios y sus posibilidades de mejorar económicamente son cada vez más difíciles.

Un reciente estudio de la migración interna destaca en más de medio siglo la tendencia de incremento en el número de migrantes, tanto en la absoluta como reciente, en cambio en la proporción hay descensos en las últimas tres décadas, a su vez en el volumen de inmigrantes y de emigrantes priman los desplazamientos en municipios que albergan tanto las dos grandes ciudades, como las ciudades intermedias, por lo que los movimientos migratorios, tienen un componente de carácter urbano. En la migración reciente la emigración en las dos principales ciudades en los últimos años se han incrementado los flujos emigratorios. Un hecho significativo en la migración interna hondureña es que la primacía del Distrito Central y San Pedro Sula como municipios atractivos en la migración reciente cambia drásticamente en los últimos años hasta convertirse en lugares con saldos negativos, especialmente San Pedro Sula (municipio con el mayor saldo migratorio negativo del país), y en menor medida el Distrito Central que también es negativo. La supremacía de estas principales DAME, donde están las principales ciudades del país se ha perdido y existe la tendencia de continuar teniendo saldos negativos en la migración reciente, por lo que es necesario explorar detenidamente el comportamiento migratorio de estos dos municipios (Flores, 2017).

\section{Metodología}

La investigación es cuantitativa, descriptiva y no experimental y traspasa el tipo descriptiva, ya que infiere elementos a considerar para futuros proyectos de investigación. La fuente principal de datos son los seis Censos de Población y Vivienda de Honduras de 1950 a 2013, considerados de la época moderna, específicamente en mayor medida el análisis se centra en los últimos tres realizados en los años 1988, 2001 y 2013 (usando datos censales no expandidos para tener una mejor comparación). Los censos hondureños han tenido las dos modalidades, de hecho hasta el año sesenta y uno y de allí en adelante se realizan con la modalidad de yure o derecho, asimismo han utilizado el concepto de hogar-vivienda, pero a partir del censo del 2001 se utiliza el concepto de hogar-unidad doméstica, más cercano a la realidad de los hogares.

Para la realización del trabajo se utiliza primordialmente las matrices básicas de migración a nivel de la División Administrativa Menor (DAME), que en este caso es el Municipio, tanto a nivel de la migración absoluta, como de la reciente, es decir dos matrices de 298 por 298 municipios, de las cuales se estiman los volúmenes, orígenes y destinos e indicadores de interés de la migración interna. Es de apuntar que algunas fueron generadas de las bases censales y otras fueron obtenidas del Proyecto de Migración Interna de América Latina y el Caribe (MIALC) que desarrolla el CELADE-CEPAL.

Las matrices básicas de migración son construidas utilizando tres preguntas básicas de los cuestionarios de cada censo; en primer lugar, la matriz básica de migración absoluta (o de toda la vida) se construye con la pregunta de lugar de nacimiento y lugar de empadronamiento, mientras la matriz básica de migración reciente se construye con la pregunta: lugar de residencia cinco años antes del censo y la pregunta lugar de empadronamiento.

Es importante informar que el Centro Latinoamericano de Demografía a través del Proyecto MIALC ha generado las matrices de migración interna de los países de América Latina que dispone de la información de los Censos de Población y Vivienda de la ronda de los años noventa, dos mil y dos mil diez, y muy recientemente ha estimado y agregado los movimientos migratorios internos entre las principales ciudades de los países, por lo que existe toda una amplia gama de información disponible para su estudio por los demógrafos, especialistas de población y de otras disciplinas interesados en las migraciones internas de cada país de la región que debe ser aprovechada para su conocimiento y formulación de políticas.

En este trabajo se hace referencia al Distrito Central y San Pedro Sula y aunque mencionemos ciudades, los valores arrojados se refieren al municipio del Distrito Central (Tegucigalpa y Comayagüela) y al municipio de San Pedro Sula.

\section{Discusión de resultados}

\subsection{Aspectos históricos}

Tegucigalpa fue fundada en 1578 por los españoles en su afán de asentarse en territorios cercanos a los yacimientos minerales. Está ubicada en el centro del país en una meseta a $990 \mathrm{msnm}$, con temperatura media anual de $22.3^{\circ} \mathrm{C}$. Es cruzada por el río Grande o Choluteca que divide a la ciudad en dos zonas, Tegucigalpa y Comayagüela que 
conforman actualmente el municipio del Distrito Central. En Tegucigalpa se ubica la sede central del Estado, el poder ejecutivo, legislativo y judicial, como de las instituciones descentralizadas, por lo que la convierten en la capital política de Honduras. Las actividades económicas principales son los servicios, comercio, construcción y la industria.

San Pedro Sula data de 1536, fue fundada por el español Pedro de Alvarado en la parte oeste del Valle de Sula en el norte del país. Tiene una altura de $83 \mathrm{msnm}$, un clima tropical húmedo con temperaturas media anual de $26.5^{\circ} \mathrm{C}$. Su extensión territorial es de $838 \mathrm{~km}^{2}$. Su economía gira en torno a la industria manufacturera y producción agroindustrial, es catalogada la capital industrial del país, sitial que adquiere por las inversiones privadas realizadas desde el enclave bananero que también se traspasa a otras industrias manufactureras que la fueron convirtiendo en un polo de desarrollo industrial de la región norte.

\subsection{Aspectos demográficos}

El Distrito Central y San Pedro Sula son los principales municipios de Honduras, que albergan a las ciudades más importantes de mayor infraestructura vial, económica, educativa, sanitaria y de instituciones públicas del país. En los aspectos demográficos estos municipios son los más poblados, urbanizados, de atracción y expulsión de población migratoria tanto interna como internacional, con mejores indicadores de fecundidad y de mortalidad que muchos del resto del país.

Los últimas seis décadas han sido de crecimiento de la población en su volumen, en 1950 ambos sólo tenían 260 mil habitantes y aumentaron al 2013 hasta alcanzar 1.6 millones. El Distrito Central siempre ha superado en su volumen de población a San Pedro Sula y esa brecha se amplió a través del tiempo, ya que la capital de la república sólo tiene municipios pequeños a su alrededor, mientras que San Pedro Sula ubicada en el Valle de Sula está rodeada de municipios intermedios que han crecido espectacularmente desde la implantación de industrias maquiladoras y agroindustriales en la zona (Gráfico No 1).

En términos relativos en ambos municipios se percibe la tendencia decreciente de las tasas de crecimiento a través del tiempo, aunque el municipio de San Pedro Sula siempre ha crecido demográficamente más que el Distrito Central en el período de estudio, a tasas entre 5.77 y 1.66 por ciento anual, mientras que el segundo entre 4.78 y 1.47 por ciento anual.
Gráfico № 1 Distrito Central y San Pedro Sula: Población total, 1950-2013

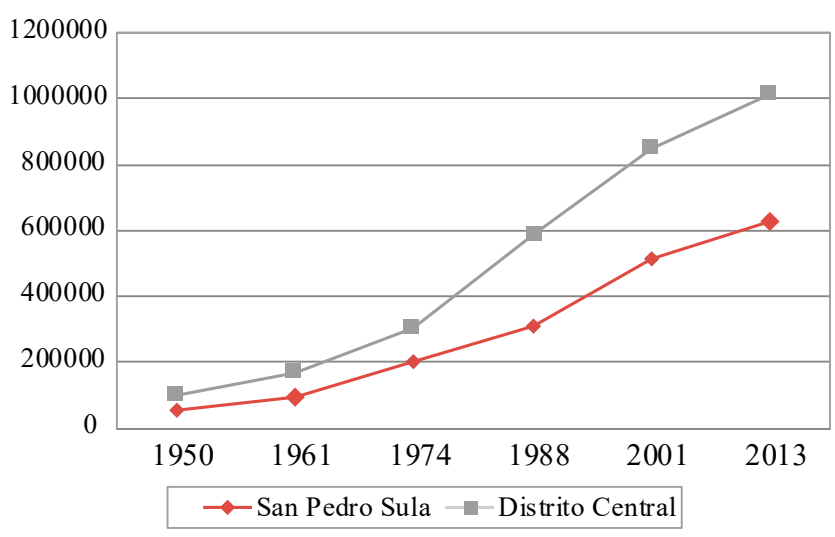

Fuente: Elaboración propia en base a datos censales 1950-2013

Otros indicadores demuestran que sus poblaciones ya están en plena transición demográfica, ya que los cambios en la reducción de la fecundidad y de la mortalidad ha llevado a modificaciones de la estructura etaria, llevando a descensos de las relaciones de dependencia de 53.1 para el Distrito Central y 56.1 para San Pedro Sula en el 2013. Por otro lado, los niveles de urbanización son elevados y giran alrededor del $92 \%$. El número de hogares se ha elevado ostensiblemente como también las jefaturas femeninas que ya alcanzan porcentajes elevados propios de zonas urbanas, en el Distrito Central de $33.9 \%$ y en San Pedro Sula de $29 \%$. El alfabetismo del Distrito Central alcanza el $87.4 \%$ de la población, mientras San Pedro Sula el 84.6\%.

Los niveles de pobreza medido a través de la insatisfacción de las necesidades básicas, San Pedro Sula 39.83\% y el Distrito Central con $43.76 \%$, ubicándose en el quinto y catorceavo lugar como municipios con menos privaciones con este indicador a nivel nacional, el cual demuestra su situación económica en comparación con el resto del país.

\subsection{Migración interna en el Distrito Central y San Pedro Sula}

- Niveles y tendencias migratorias

Los volúmenes de poblaciones involucradas en el fenómeno migratorio interno en el país ha aumentado considerablemente en las últimas décadas, sin embargo, sus proporciones disminuyen aunque con menor velocidad en cada medición censal. La migración neta es positiva en ambos municipios aunque hay una disminución ostensible del número de migrantes en el último ejercicio censal, principalmente en San Pedro Sula. 
En la migración absoluta de los dos municipios estudiados se evidencia que la migración interna bruta (inmigrantes más emigrantes) ha involucrado niveles que han aumentado de 424,722 en 1988 a 644,160 mil personas en el 2013, pero sus proporciones se reducen en los inmigrantes y se han mantenido oscilantes en el tiempo en los emigrantes (Cuadro $\mathrm{N}^{\circ}$ 1).
En el comportamiento de la migración reciente hay un desaceleramiento de la migración bruta en 2013 en ambos municipios, lo mismo sucede en la migración neta. En las proporciones de inmigrantes es notorio el descenso de ellos a través del tiempo, que implica la pérdida de la atracción en ambas ciudades, mientras que en los emigrantes hay una tendencia al aumento, incluso en la tasas de migración neta son negativas en ambos municipios, principalmente en San Pedro Sula (Cuadro $\mathrm{N}^{\circ} 2$ ).

Cuadro №1 Distrito Central y San Pedro Sula: cuadro resumen de migración absoluta, 1988, 2001 y 2013

\begin{tabular}{|c|c|c|c|c|c|c|c|c|c|}
\hline Municipios & $\begin{array}{l}\text { Población } \\
\text { residente en } \\
1988\end{array}$ & $\begin{array}{l}\text { Población } \\
\text { nacida en el } \\
\text { municipio }\end{array}$ & $\begin{array}{l}\text { Residentes } \\
\text { nacidos en } \\
\text { el municipio }\end{array}$ & Emigrantes & Inmigrantes & $\begin{array}{l}\text { Migración } \\
\text { Neta }\end{array}$ & $\begin{array}{l}\text { Migración } \\
\text { Bruta }\end{array}$ & $\begin{array}{c}\% \\
\text { Emigrantes }\end{array}$ & $\%$ Inmigrantes \\
\hline Distrito Central & 562,143 & 411,536 & 366,446 & 45,090 & 195,697 & 150,607 & 240,787 & 10.96 & 34.81 \\
\hline San Pedro Sula & 290,746 & 229,725 & 168,268 & 61,457 & 122,478 & 61,021 & 183,935 & 26.75 & 42.13 \\
\hline $\begin{array}{l}\text { Total } 2 \\
\text { municipios }\end{array}$ & 852,889 & 641,261 & 534,714 & 106,547 & 318,175 & 211,628 & 424,722 & 16.62 & 37.31 \\
\hline Total de País & 4112,367 & 4112,367 & 2981,903 & 1130,464 & 1130,464 & 0 & 2260,928 & 27.49 & 27.49 \\
\hline Municipios & $\begin{array}{c}\text { Población } \\
\text { residente en } \\
2001 \\
\end{array}$ & $\begin{array}{c}\text { Población } \\
\text { nacida en el } \\
\text { municipio }\end{array}$ & $\begin{array}{c}\text { Residentes } \\
\text { nacidos en } \\
\text { el municipio } \\
\end{array}$ & Emigrantes & Inmigrantes & $\begin{array}{l}\text { Migración } \\
\text { Neta }\end{array}$ & $\begin{array}{l}\text { Migración } \\
\text { Bruta }\end{array}$ & $\begin{array}{c}\% \\
\text { Emigrantes }\end{array}$ & $\%$ Inmigrantes \\
\hline Distrito Central & 827,941 & 687,623 & 617,225 & 70,398 & 210,716 & 140,318 & 281,114 & 10.24 & 25.45 \\
\hline San Pedro Sula & 495,539 & 402,991 & 323,219 & 79,772 & 172,320 & 92,548 & 252,092 & 19.79 & 34.77 \\
\hline $\begin{array}{l}\text { Total } 2 \\
\text { municipios }\end{array}$ & 1323,480 & 1090,614 & 940,444 & 150,170 & 383,036 & 232,866 & 533,206 & 13.77 & 28.94 \\
\hline Total de País & 5963,794 & 5963,794 & 4112,367 & 1390,823 & 1390,823 & 0 & 2781,646 & 23.32 & 23.32 \\
\hline Municipios & $\begin{array}{c}\text { Población } \\
\text { residente en } \\
2013\end{array}$ & $\begin{array}{c}\text { Población } \\
\text { nacida en el } \\
\text { municipio }\end{array}$ & $\begin{array}{c}\text { Residentes } \\
\text { nacidos en } \\
\text { el municipio }\end{array}$ & Emigrantes & Inmigrantes & $\begin{array}{l}\text { Migración } \\
\text { Neta }\end{array}$ & $\begin{array}{l}\text { Migración } \\
\text { Bruta }\end{array}$ & $\begin{array}{c}\% \\
\text { Emigrantes }\end{array}$ & $\%$ Inmigrantes \\
\hline Distrito Central & 1007,585 & 909,687 & 795,955 & 113,912 & 211,630 & 97,718 & 325,542 & 12.52 & 21.00 \\
\hline San Pedro Sula & 624,048 & 590,520 & 447,975 & 142,545 & 176,073 & 33,528 & 318,618 & 24.14 & 28.21 \\
\hline $\begin{array}{l}\text { Total } 2 \\
\text { municipios }\end{array}$ & 1631,633 & 1500,207 & 1243,930 & 256,457 & 387,703 & 131,246 & 644,160 & 17.09 & 23.76 \\
\hline Total de País & 7625,156 & 7625,156 & 590,312 & 1714,844 & 1714,844 & 0 & 3429,688 & 22.49 & 22.49 \\
\hline
\end{tabular}

Fuente: Elaboración propia en base a datos de censales sin expandir ,1988, 2001 y 2013

Cuadro №2 Distrito Central y San Pedro Sula : cuadro resumen de migración reciente, 1988, 2001 y 2013

\begin{tabular}{|c|c|c|c|c|c|c|c|c|c|c|}
\hline Municipios & \begin{tabular}{|c|}
$\begin{array}{c}\text { Población } \\
\text { residente en } \\
1988\end{array}$ \\
\end{tabular} & \begin{tabular}{|c|}
$\begin{array}{c}\text { Población } \\
\text { residente en } \\
1983\end{array}$ \\
\end{tabular} & $\begin{array}{l}\text { Residiendo } \\
\text { mismo } \\
\text { municipio }\end{array}$ & Emigrantes & Inmigrantes & $\begin{array}{l}\text { Migración } \\
\text { Neta }\end{array}$ & $\begin{array}{c}\text { Migración } \\
\text { Bruta }\end{array}$ & $\begin{array}{c}\text { Tasa de } \\
\text { Emigrantes }\end{array}$ & $\begin{array}{l}\text { Tasa de } \\
\text { Inmigrantes }\end{array}$ & $\begin{array}{l}\text { Tasa de } \\
\text { Migración } \\
\text { Neta } \\
\end{array}$ \\
\hline Distrito Central & 479,388 & 449,357 & 436,619 & 12,738 & 42,769 & 30,031 & 55,507 & 5.49 & 18.42 & 12.93 \\
\hline San Pedro Sula & 254,010 & 245,890 & 230,148 & 15,742 & 23,862 & 8,120 & 39,604 & 12.6 & 19.09 & 6.5 \\
\hline Total 2 municipid & 733,398 & 695,247 & 666,767 & 28,480 & 66,631 & 38,151 & 95,111 & 7.97 & 18.66 & 10.68 \\
\hline Total País & $3,397,022$ & $3,397,022$ & $3,164,450$ & 232,572 & 232,572 & 0 & 465,144 & 13.69 & 13.69 & 0 \\
\hline Municipios & \begin{tabular}{|c|}
$\begin{array}{c}\text { Población } \\
\text { residente en } \\
2001\end{array}$ \\
\end{tabular} & \begin{tabular}{|c|}
$\begin{array}{c}\text { Población } \\
\text { residente en } \\
1996\end{array}$ \\
\end{tabular} & $\begin{array}{c}\text { Residiendo } \\
\text { mismo } \\
\text { municipio } \\
\end{array}$ & Emigrantes & Inmigrantes & $\begin{array}{l}\text { Migración } \\
\text { Neta }\end{array}$ & $\begin{array}{c}\text { Migración } \\
\text { Bruta }\end{array}$ & $\begin{array}{l}\text { Tasa de } \\
\text { Emigrantes }\end{array}$ & $\begin{array}{l}\text { Tasa de } \\
\text { Inmigrantes }\end{array}$ & $\begin{array}{c}\text { Tasa de } \\
\text { Migración } \\
\text { Neta } \\
\end{array}$ \\
\hline Distrito Central & 745,981 & 734,529 & 710,605 & 23,924 & 35,376 & 11,452 & 59,300 & 6.46 & 9.56 & 3.09 \\
\hline San Pedro Sula & 443,449 & 436,560 & 406,453 & 30,107 & 36,996 & 6,889 & 67,103 & 13.68 & 16.82 & 3.13 \\
\hline Total 2 municipid & $1,189,430$ & $1,171,089$ & $1,117,058$ & 54,031 & 72,372 & 18,341 & 126,403 & 9.16 & 12.26 & 3.11 \\
\hline Total País & $5,166,813$ & $5,166,813$ & $4,854,191$ & 312,622 & 312,622 & 0 & 625,244 & 12.1 & 12.1 & 0 \\
\hline Municipios & \begin{tabular}{|c|} 
Población \\
residente en \\
2013 \\
\end{tabular} & \begin{tabular}{|c|}
$\begin{array}{c}\text { Población } \\
\text { residente en } \\
2008\end{array}$ \\
\end{tabular} & $\begin{array}{c}\text { Residiendo } \\
\text { mismo } \\
\text { municipio } \\
\end{array}$ & Emigrantes & Inmigrantes & $\begin{array}{l}\text { Migración } \\
\text { Neta }\end{array}$ & $\begin{array}{c}\text { Migración } \\
\text { Bruta }\end{array}$ & $\begin{array}{c}\text { Tasa de } \\
\text { Emigrantes }\end{array}$ & $\begin{array}{l}\text { Tasa de } \\
\text { Inmigrantes }\end{array}$ & $\begin{array}{c}\text { Tasa de } \\
\text { Migración } \\
\text { Neta } \\
\end{array}$ \\
\hline Distrito Central & 909,257 & 910,695 & 883,024 & 27,671 & 26,233 & $-1,438$ & 53,904 & 6.08 & 5.77 & -0.32 \\
\hline San Pedro Sula & 559,337 & 571,670 & 531,514 & 40,156 & 27,823 & $-12,333$ & 67,979 & 14.2 & 9.84 & -4.36 \\
\hline Total 2 municipid & $1,468,594$ & $1,482,365$ & $1,414,538$ & 67,827 & 54,056 & $-13,771$ & 121,883 & 9.19 & 7.33 & -1.87 \\
\hline Total Pais & $6,735,599$ & $6,735,599$ & $6,413,941$ & 321,658 & 321,658 & 0 & 643,316 & 9.55 & 9.55 & 0 \\
\hline
\end{tabular}


- Migración neta

Desde el punto de vista migratorio los dos municipios han sido atractivos, una forma de comprobar esto es que generalmente han tenido saldos migratorios positivos con respecto a los demás municipios del país y esto se ha manifestado más en la migración absoluta.

En el caso de la migración reciente esta tendencia ha evolucionado hacia la reducción del número de municipios con los que se tienen saldos migratorios positivos, principalmente para San Pedro Sula donde se redujo de 240 a 115 en el período 2001-2013, en otras palabras actualmente con $57 \%$ de los municipios tiene migración neta negativa (Cuadro $\mathrm{N}^{\circ} 3$ ).

Cuadro N³ Distrito Central y San Pedro Sula: número de municipios por migración absoluta y reciente según saldo, 1988,2001 y 2013

\begin{tabular}{|c|c|c|c|c|c|c|c|}
\hline \multirow[t]{2}{*}{ Municipio } & \multirow[t]{2}{*}{ Saldo } & \multicolumn{3}{|c|}{$\begin{array}{l}\text { Migración Absoluta o de } \\
\text { toda la vida }\end{array}$} & \multicolumn{3}{|c|}{ Migración Reciente } \\
\hline & & 1988 & 2001 & 2013 & 1988 & 2001 & 2013 \\
\hline \multirow{4}{*}{$\begin{array}{l}\text { Distrito } \\
\text { Central }\end{array}$} & Positivo & 279 & 273 & 247 & 264 & 225 & 146 \\
\hline & \begin{tabular}{|l|} 
Negativo \\
\end{tabular} & 9 & 14 & 49 & 21 & 61 & 141 \\
\hline & Equilibrio & 0 & 0 & 1 & 3 & 11 & 10 \\
\hline & Total & 288 & 287 & 297 & 288 & 297 & 297 \\
\hline \multirow{4}{*}{$\begin{array}{l}\text { San Pedro } \\
\text { Sula }\end{array}$} & Positivo & 273 & 280 & 250 & 236 & 240 & 115 \\
\hline & \begin{tabular}{|l|} 
Negativo \\
\end{tabular} & 14 & 17 & 47 & 33 & 46 & 171 \\
\hline & Equilibrio & 1 & 0 & 0 & 19 & 11 & 11 \\
\hline & Total & 288 & 297 & 297 & 288 & 297 & 297 \\
\hline
\end{tabular}

Fuente: Elaboración propia en base a datos censales sin expandir, 1988, 2001 y 2013

En el Distrito Central en el último ejercicio censal también se ha producido una reducción del número de municipios con los cuales mantiene saldos positivos y esto se hace más visible en la migración reciente que también han aumentado el número de municipios con los cuales mantiene saldos migratorios negativos, sin duda que este comportamiento decreciente implica que los flujos migratorios de los municipios de estudio se redireccionan a municipios aledaños y a otros que albergan una ciudad donde posiblemente las actividades laborales 0 de emprendimiento se están expandiendo, siendo esto más visible en la migración reciente, no sucediendo tanto en la migración absoluta que mantiene los saldos positivos en los intercambios migratorios (Cuadro $\mathrm{N}^{\circ} 5$ ).

En cambio en San Pedro Sula sus mayores saldos positivos recientes son con el municipio del Distrito Central donde hay un fuerte intercambio que ya le favorece, a su vez mantiene los orígenes de migrantes del occidente y municipios del litoral (Cuadro $\mathrm{N}^{\circ} 6$ ).
Cuadro N5 Distrito Central: municipios con mayor y menor Migración Neta Reciente, 1988, 2001 y 2013

\begin{tabular}{|c|c|c|c|c|c|c|c|c|}
\hline Cod & Municipios & \begin{tabular}{|c|} 
Saldo \\
Migratorio \\
1988-1983 \\
\end{tabular} & Cod & Municipios & \begin{tabular}{|c|} 
Saldo \\
Migratorio \\
2001-1996
\end{tabular} & Cod & Municipios & \begin{tabular}{c|} 
Saldo \\
Migratorio \\
2013-2008
\end{tabular} \\
\hline 601 & \begin{tabular}{|l|} 
Choluteca \\
\end{tabular} & 2,120 & 703 & Danlí & 1,473 & 601 & Choluteca & 957 \\
\hline 1501 & Juticalpa & 1,547 & 601 & Choluteca & 795 & 1501 & Juticalpa & 482 \\
\hline 703 & Danlí & 1,183 & 611 & Pespire & 752 & 703 & Danlí & 305 \\
\hline 611 & Pespire & 1,125 & 1501 & Juticalpa & 590 & 611 & Pespire & 268 \\
\hline 1701 & Nacaome & 912 & 1701 & Nacaome & 470 & 1707 & Langue & 235 \\
\hline 615 & $\begin{array}{l}\text { San Marcos } \\
\text { de Colón }\end{array}$ & 712 & 610 & Orocuina & 446 & 615 & $\begin{array}{l}\text { San Marcos } \\
\text { de Colón }\end{array}$ & 232 \\
\hline 605 & El Corpus & 613 & 1707 & Langue & 406 & 606 & El Triunfo & 224 \\
\hline 816 & Sabanagrande & 607 & 606 & El Triunfo & 360 & 701 & Yuscarán & 217 \\
\hline 610 & Orocuina & 605 & 615 & $\begin{array}{l}\text { San Marcos de } \\
\text { Colón }\end{array}$ & 359 & 603 & $\begin{array}{l}\text { Concepción de } \\
\text { Maria }\end{array}$ & 208 \\
\hline 1709 & San Lorenzo & 605 & 803 & Cedros & 358 & 802 & Alubaren & 188 \\
\hline 823 & Santa Lucía & -175 & 501 & $\begin{array}{l}\text { San Pedro } \\
\text { Sula }\end{array}$ & $-1,436$ & 501 & $\begin{array}{l}\text { San Pedro } \\
\text { Sula }\end{array}$ & -938 \\
\hline 502 & Choloma & -167 & 502 & Choloma & $-1,048$ & 822 & Santa Ana & -805 \\
\hline 817 & $\begin{array}{l}\text { San Antonio } \\
\text { de Oriente }\end{array}$ & -58 & 511 & Villanueva & -684 & 823 & Santa Lucía & -730 \\
\hline 511 & Villanueva & -54 & 823 & Santa Lucía & -429 & 826 & $\begin{array}{l}\text { Valle de } \\
\text { Angeles }\end{array}$ & -713 \\
\hline 1006 & Intibucá & -49 & 708 & Morocelí & -306 & 502 & Choloma & -683 \\
\hline 512 & La Lima & -30 & 826 & $\begin{array}{l}\text { Valle de } \\
\text { Angeles }\end{array}$ & -297 & 511 & Villaneuva & -592 \\
\hline 319 & \begin{tabular}{|l|} 
Villa de San \\
Antonio \\
\end{tabular} & -24 & 318 & Siguatepeque & -245 & 825 & Tatumbla & -450 \\
\hline 106 & San Francisco & -23 & 817 & $\begin{array}{l}\text { San Antonio } \\
\text { de Oriente }\end{array}$ & -228 & 318 & Siguatepeque & -370 \\
\hline 826 & \begin{tabular}{|l|} 
Valle de \\
Angeles \\
\end{tabular} & -23 & 506 & Puerto Cortés & -160 & 824 & Talanga & -224 \\
\hline 102 & El Porvenir & -22 & 510 & $\begin{array}{l}\text { Santa Cruz de } \\
\text { Yojoa }\end{array}$ & -141 & 817 & $\begin{array}{l}\text { San Antonio } \\
\text { de Oriente }\end{array}$ & -171 \\
\hline
\end{tabular}

Fuente: Elaboración propia en base a datos censales sin expandir, 1988,2001 y 2013

Cuadro $N^{\circ} 6$ San Pedro Sula: municipios con mayor y menor Migración Neta Reciente, 1988, 2001 y 2013

\begin{tabular}{|c|c|c|c|c|c|c|c|c|}
\hline Cod & |Municipio: & \begin{tabular}{|c|} 
Saldo \\
Migratorio \\
1988-1983 \\
\end{tabular} & cod & | Municipios | & \begin{tabular}{|c|} 
Saldo \\
Migratorio \\
2001-1996 \\
\end{tabular} & cod & Municipios & \begin{tabular}{|c|} 
Saldo \\
Migratorio \\
2013-2008 \\
\end{tabular} \\
\hline 107 & Tela & 562 & 801 & \begin{tabular}{|l} 
Distrito \\
Central
\end{tabular} & 1,436 & 801 & Distrito Central & 938 \\
\hline 1627 & $\begin{array}{ll}\text { Las Vegas } \\
\end{array}$ & 538 & 1601 & \begin{tabular}{|l|} 
Santa \\
Bárbara
\end{tabular} & 838 & 1601 & Santa Bárbara & 737 \\
\hline 1613 & Macuelizo & 507 & 1807 & \begin{tabular}{|l|l|l|l|l|l|l} 
Olanchito \\
\end{tabular} & 719 & 201 & Trujillo & 359 \\
\hline 1601 & \begin{tabular}{|c|}
$\begin{array}{c}\text { Santa } \\
\text { Bárbara }\end{array}$ \\
\end{tabular} & 428 & 107 & Tela & 716 & 401 & \begin{tabular}{|l|} 
Santa Rosa de \\
Copán
\end{tabular} & 329 \\
\hline 1618 & Quimistán & 399 & 1801 & Yoro & 672 & 1612 & llama & 298 \\
\hline 1807 & \begin{tabular}{|l|} 
Olanchito \\
\end{tabular} & 387 & 1620 & San Luis & 607 & 1501 & Juticalpa & 294 \\
\hline 401 & $\begin{array}{l}\text { Santa } \\
\text { Rosa de } \\
\text { Copán }\end{array}$ & 365 & 401 & \begin{tabular}{|} 
Santa Rosa \\
de Copán
\end{tabular} & 606 & 1801 & Yoro & 267 \\
\hline 101 & La Ceiba & 341 & 101 & La Ceiba & 495 & 1617 & \begin{tabular}{|l|} 
Protección \\
\end{tabular} & 255 \\
\hline 1626 & Trinidad & 290 & 1806 & Morazán & 483 & 1620 & San Luis & 247 \\
\hline 503 & Omoa & 277 & 1613 & \begin{tabular}{|l|} 
Macuelizo \\
\end{tabular} & 432 & 1807 & \begin{tabular}{|l|} 
Olanchito \\
\end{tabular} & 230 \\
\hline 502 & Choloma & $-3,012$ & 511 & \begin{tabular}{|l|} 
Villanueva \\
\end{tabular} & -4.932 & 5 511 & |Villanueva & $-4,952$ \\
\hline 512 & La Lima & $-1,362$ & 502 & Choloma & $-4,771$ & 502 & Choloma & $\begin{array}{l}-3,3061 \\
-3,861\end{array}$ \\
\hline 511 & Villanueva & -445 & 509 & \begin{tabular}{|l|} 
San Manuel \\
\end{tabular} & -839 & 509 & San Manuel & $-1,469$ \\
\hline 801 & \begin{tabular}{|l}
$\begin{array}{l}\text { Distrito } \\
\text { Central }\end{array}$ \\
\end{tabular} & -195 & 504 & Pimienta & -389 & 512 & La Lima & $-1,178$ \\
\hline 509 & \begin{tabular}{|l|}
$\begin{array}{l}\text { San } \\
\text { Manuel }\end{array}$ \\
\end{tabular} & -99 & 512 & La Lima & -352 & 1618 & Quimistán & $-1,035$ \\
\hline 1101 & Roatán & -84 & 510 & \begin{tabular}{|l} 
Santa Cruz \\
de Yojoa
\end{tabular} & -196 & 504 & Pimienta & -527 \\
\hline 9 & $\begin{array}{l}\text { Villa de } \\
\text { San } \\
\text { Antonio }\end{array}$ & -36 & 506 & \begin{tabular}{|l} 
Puerto \\
Cortés
\end{tabular} & -162 & 510 & \begin{tabular}{|l|}
$\begin{array}{l}\text { Santa Cruz de } \\
\text { Yojoa }\end{array}$ \\
\end{tabular} & -414 \\
\hline 1103 & \begin{tabular}{|l} 
José \\
Santos \\
Guardiola
\end{tabular} & -35 & 505 & Potrerillos & -96 & 506 & Puerto Cortés & -380 \\
\hline 817 & $\begin{array}{l}\text { San } \\
\text { Antonio de } \\
\text { Oriente }\end{array}$ & -28 & 1616 & Petoa & -84 & 318 & Siguatepeque & -290 \\
\hline 100 & |ntibucá & -27 & 318 & Siguatepeque & -81 & 1606 & \begin{tabular}{|l} 
San José de \\
Colina
\end{tabular} & -207 \\
\hline
\end{tabular}

Fuente: Elaboración propia en base a datos censales sin expandir, 1988, 2001 y 2013

En los intercambios de San Pedro Sula que llevan a una migración neta negativa son notorios en los municipios adyacentes en el Valle de Sula, como Villanueva, Choloma, San Manuel, La Lima, Pimienta, Santa Cruz de Yojoa y Puerto Cortés, y en menor medida en municipios del departamento de Santa Bárbara. 
Diagráma Nº 1 Distrtito Central y San Pedro Sula: orígenes y destinos de Migración Asoluta, DAME 2013

(mayores de 2000 personas)

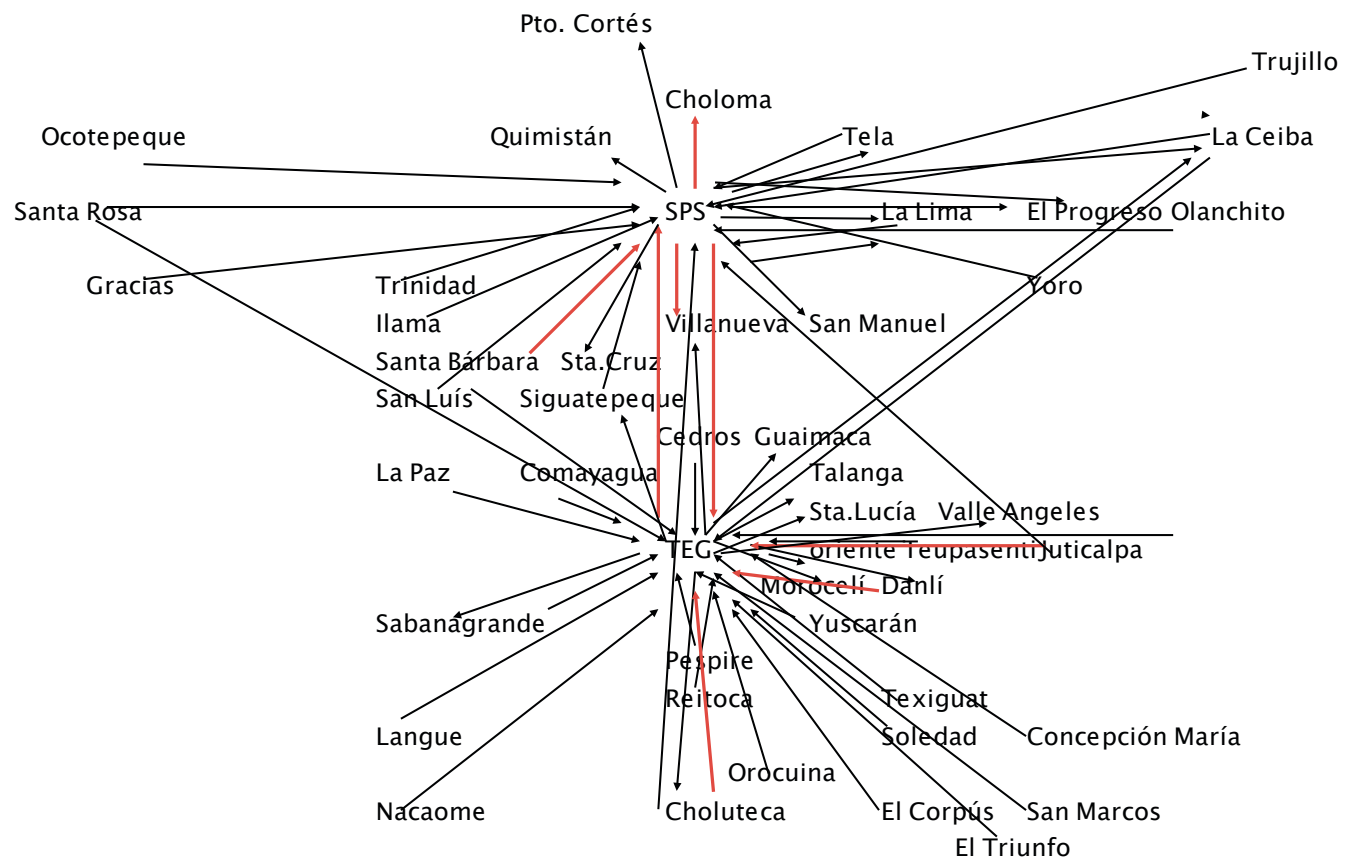

Fuente: Elaboración propia

\subsection{Orígenes y destinos migratorios}

En los principales flujos migratorios de toda la vida en el país es notoria la existencia de tres subsistemas en los cuales gravitan la mayoría de los desplazamientos, uno en el Valle de Sula cuyo centro es San Pedro Sula, el otro en el centro en relación al Distrito Central y el tercero en la parte nororiental ligada principalmente al litoral que gravita en La Ceiba.

En el Distrito Central los principales flujos provienen del sur (departamento de Choluteca, Valle y el mismo Francisco Morazán) y del oriente (departamento de EI Paraíso y Olancho) y los generados desde el nororiente como de Atlántida y el norte de Cortés y el occidente, especialmente de Copán. Específicamente los mayores flujos de inmigrantes de toda la vida hacia el Distrito Central tienen su origen primordialmente del municipio de Choluteca, seguidamente en menor medida de Danlí y Juticalpa, después de Pespire, San Pedro Sula, Nacaome, San Marcos de Colón y Comayagua entre otros. En cambio los destinos de los emigrantes de toda la vida desde el Distrito Central son para el municipio de San Pedro Sula como principal flujo, después siguen los municipios de Talanga, Danlí, San Antonio de Oriente, Comayagua, Choloma, La Ceiba, Guaimaca y Santa Lucía entre otros, que sin duda muestran como de este origen aparecen flujos migratorios significativos a municipios vecinos del mismo departamento como de aquellos aledaños, qué decir de aquellos que son para municipios no cercanos pero que tienen rubros o actividades económicas de auge generadores de empleos (Diagrama $\mathrm{N}^{\circ} 1$ ).

Para San Pedro Sula los orígenes de los migrantes absolutos sus mayores flujos proceden del Distrito Central, Santa Bárbara, Santa Rosa de Copán, Tela, Yoro, La Ceiba, El Progreso, Choluteca y Olanchito, entre otros. En cambio en la emigración los destinos son para Choloma, Villanueva, La Lima, San Manuel, Distrito Central, El Progreso, Santa Cruz de Yojoa, Quimistán, Puerto Cortés, entre otros.

En la migración reciente (cinco años antes) los flujos mayores de mil personas en el 2013 para ambos municipios sólo hay quince eventos, para el Distrito Central sus orígenes más destacados son de San Pedro Sula, Choluteca, Danlí y Juticalpa, mientras los destinos específicos son para los municipios de San Pedro Sula y Danlí (Diagrama $N^{\circ} 2$ ).

En San Pedro Sula los migrantes recientes proceden del Distrito Central, Choloma, Santa Bárbara y La Ceiba, mientras desde este origen sus destinos son para Villanueva, Choloma, La Lima, Distrito Central, San Manuel y Quimistán. 
Diagrama $\mathbf{N}^{\circ} 2$ Distrtito Central y San Pedro Sula: orígenes y destinos de Migración Reciente, DAME 2013

(mayores de 1000 personas)

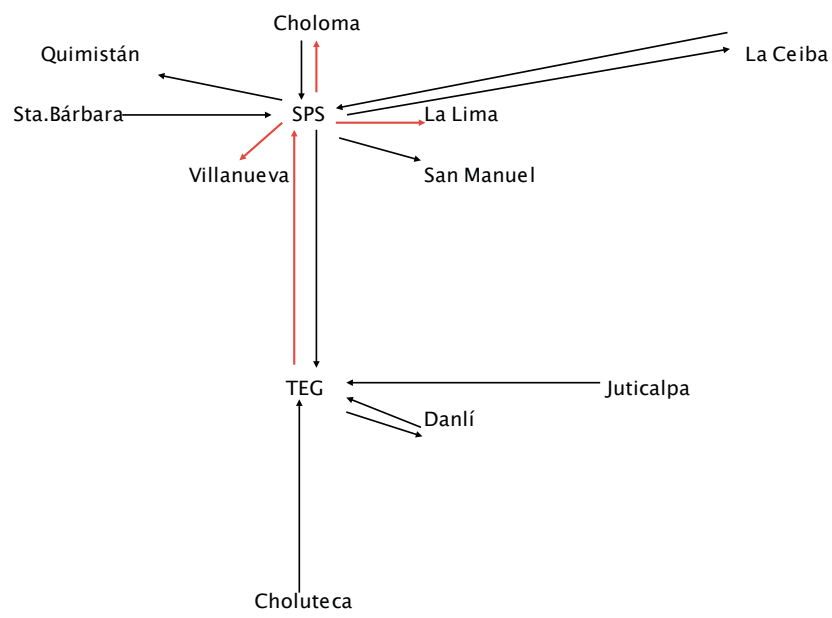

Fuente: Elaboración propia

\section{- Migración cercana y lejana}

Con la información de la pregunta de residencia cinco años antes de cada censo de población como de lugar de residencia actual se construye la matriz de migración reciente, a su vez se puede derivar otra matriz para determinar los intercambios migratorios de acuerdo a la cercanía o lejanía del lugar de residencia, que en este caso es determinado por el municipio. Se considera migración reciente cercana a nivel DAME aquellos intercambios que se producen entre el municipio de residencia y aquellos que están en la misma DAM, y lejana aquellos intercambios entre el municipio de residencia y los demás municipios que están ubicados en otras DAM. Como resultado tendremos una idea de intercambios migratorios con una aproximación de la distancia entre ellos.

La primer medición para el Distrito Central es de los movimientos migratorios recientes entre 1996-2001, indican que tiene una migración neta de 11,452 personas y una tasa de migración de 3.09 por mil, a su vez esta tendencia es debido a que tanto el intercambio migratorio cercano y lejano son positivos, aunque es preciso decir que su influencia es debido más que todo por al intercambio migratorio lejano que es más influyente en su comportamiento (Cuadro $\mathrm{N}^{\circ} 7$ ).

En la medición del 2008-2013 los resultados del Distrito Central ya muestran una migración neta negativa de -1,438 personas y una tasa de migración neta de -0.32 , siendo este comportamiento producto del desequilibrio que se produce en el intercambio con los municipios cercanos (Cuadro $\mathrm{N}^{\circ} 8$ ).

Cuadro N7 Distrito Central: matriz de Migración Reciente con otros municipios del país agrupados en categorías de cercanía 2001-1996

\begin{tabular}{|c|c|c|c|c|c|c|}
\hline \multirow[b]{2}{*}{$\begin{array}{l}\text { Zona de } \\
\text { residencia } \\
\text { al momento } \\
\text { del censo } \\
\text { (2001) }\end{array}$} & \multicolumn{3}{|c|}{$\begin{array}{c}\text { Zona de residencia cinco años antes } \\
\text { del censo (1996) }\end{array}$} & \multirow[b]{2}{*}{$\begin{array}{l}\text { Total } \\
\text { censo }\end{array}$} & \multirow[b]{2}{*}{$\begin{array}{c}\text { Migración } \\
\text { neta (total } \\
\text { censo - } \\
\text { total cinco } \\
\text { años antes }\end{array}$} & \multirow[b]{2}{*}{$\begin{array}{c}\text { Tasa de } \\
\text { migración } \\
\text { neta (por } \\
\text { mil) }\end{array}$} \\
\hline & $\begin{array}{l}\text { Distrito } \\
\text { Central }\end{array}$ & $\begin{array}{l}\text { Otros } \\
\text { municipios } \\
\text { de } \\
\text { Francisco } \\
\text { Morazán }\end{array}$ & $\begin{array}{l}\text { Otros } \\
\text { municipios } \\
\text { fuera de } \\
\text { Francisco } \\
\text { Morazán }\end{array}$ & & & \\
\hline \begin{tabular}{|l|} 
Distrito \\
Central \\
\end{tabular} & 710,605 & 5,704 & 29,672 & 745,981 & 11,452 & 3.09 \\
\hline \begin{tabular}{|l|} 
Otros \\
municipios \\
de \\
Francisco \\
Morazán \\
\end{tabular} & 4,518 & 212,919 & 4,566 & 222,003 & & \\
\hline \begin{tabular}{|l|} 
Otros \\
municipios \\
fuera de \\
Francisco \\
Morazán \\
\end{tabular} & 19,406 & 3,956 & 4175,467 & 4198,829 & & \\
\hline Total & 734,529 & 222,579 & 4209,705 & 5166,813 & & \\
\hline
\end{tabular}

Fuente: Elaboración propia en base a datos de la Matriz Básica de Migración Reciente, MIALC-CELADE

Cuadro No8 Distrito Central: matriz de Migración Reciente con otros municipios del país agrupados en categorías de cercanía 2013-2008

\begin{tabular}{|c|c|c|c|c|c|c|}
\hline \multirow[b]{2}{*}{$\begin{array}{l}\text { Zona de } \\
\text { residencia } \\
\text { al momento } \\
\text { del censo } \\
\text { (2013) }\end{array}$} & \multicolumn{3}{|c|}{$\begin{array}{l}\text { Zona de residencia cinco años antes } \\
\text { del censo (2008) }\end{array}$} & \multirow[b]{2}{*}{$\begin{array}{l}\text { Total } \\
\text { censo }\end{array}$} & \multirow[b]{2}{*}{$\begin{array}{l}\text { Migración } \\
\text { neta (total } \\
\text { censo - } \\
\text { total cinco } \\
\text { años antes }\end{array}$} & \multirow[b]{2}{*}{$\begin{array}{l}\text { Tasa de } \\
\text { migración } \\
\text { neta (por } \\
\text { mil) }\end{array}$} \\
\hline & $\begin{array}{l}\text { Distrito } \\
\text { Central }\end{array}$ & $\begin{array}{c}\text { Otros } \\
\text { municipios } \\
\text { de } \\
\text { Francisco } \\
\text { Morazán }\end{array}$ & $\begin{array}{c}\text { Otros } \\
\text { municipios } \\
\text { fuera de } \\
\text { Francisco } \\
\text { Morazán }\end{array}$ & & & \\
\hline $\begin{array}{l}\text { Distrito } \\
\text { Central }\end{array}$ & 883,024 & 4,089 & 22,144 & 909,257 & $-1,438$ & -0.32 \\
\hline $\begin{array}{l}\text { Otros } \\
\text { municipios } \\
\text { de } \\
\text { Francisco } \\
\text { Morazán } \\
\end{array}$ & 7,098 & 278,815 & 7,184 & 293,097 & & \\
\hline \begin{tabular}{|l|} 
Otros \\
municipios \\
fuera de \\
Francisco \\
Morazán \\
\end{tabular} & 20,573 & 260,570 & 5252,102 & 5533,245 & & \\
\hline Total & 910,695 & 543,474 & 5281,430 & 6735,599 & & \\
\hline
\end{tabular}

Fuente: Elaboración propia en base a datos de la matriz básica de migración reciente, de base censal 2013

El comportamiento migratorio del Distrito Central en relación a la migración reciente, que es el mejor acercamiento a los desplazamientos, ya que está determinado por el período corto de medición que es de cinco años, todo llega a indicar que hay una desaceleración de la atracción del municipio como destino migratorio reciente entre las dos mediciones, mientras en 1996-2001 es todavía positiva, para 2008-2013 cambia espectacularmente a negativa, principalmente por el intercambio a municipios cercanos, mientras que la lejana todavía hay saldos de atracción positivos. Todo esto indica que en el intercambio del Distrito Central aunque existan flujos hacia ella en los últimos años más bien adquieren supremacía los que se dirigen hacia los municipios cercanos de la misma DAM (Gráfico № 2). 


\section{Gráfico $\mathbf{N}^{\circ} 2$ Distrito Central: migración neta cercana y lejana, 2001-1996 y 2013-2008}

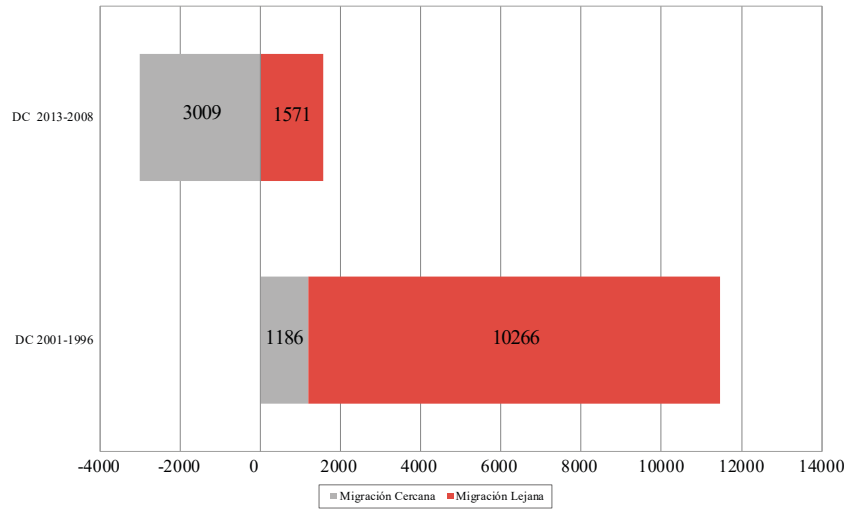

Fuente: Elaboración propia en base a datos de la Matriz Básica de Migración Reciente. 2001 y 2013

En el caso del municipio de San Pedro Sula en el período 1996-2001 aunque se tiene una migración neta positiva de 6,889 personas y una tasa de migración de 3.13 por mil, ya asoma una pérdida de atracción en el intercambio con municipios cercanos sin embargo, en el lejano todavía es de atracción y es mayoritario (Cuadro $\mathrm{N}^{\circ}$ 9).

Cuadro Nº San Pedro Sula: matriz de migración reciente con otros municipios del país agrupados en categorías de cercanía 2001-1996

\begin{tabular}{|c|c|c|c|c|c|c|}
\hline \multirow{2}{*}{$\begin{array}{l}\text { Zona de } \\
\text { residencia } \\
\text { al momento } \\
\text { del censo } \\
\text { (2001) }\end{array}$} & \multicolumn{3}{|c|}{$\begin{array}{l}\text { Zona de residencia cinco años } \\
\text { antes del censo (1996) }\end{array}$} & \multirow[b]{2}{*}{$\begin{array}{l}\text { Total } \\
\text { censo }\end{array}$} & \multirow{2}{*}{$\begin{array}{l}\text { Migración } \\
\text { neta (total } \\
\text { censo- } \\
\text { total cinco } \\
\text { años antes }\end{array}$} & \multirow{2}{*}{$\begin{array}{l}\text { Tasa de } \\
\text { migración } \\
\text { neta (por } \\
\text { mil) }\end{array}$} \\
\hline & $\begin{array}{l}\text { San } \\
\text { Pedro } \\
\text { Sula }\end{array}$ & $\begin{array}{c}\text { Otros } \\
\text { municipios } \\
\text { de } \\
\text { Cortés }\end{array}$ & $\begin{array}{c}\text { Otros } \\
\text { municipios } \\
\text { fuera de } \\
\text { Cortés }\end{array}$ & & & \\
\hline $\begin{array}{l}\text { San Pedro } \\
\text { Sula }\end{array}$ & 406,453 & 5,122 & 31,874 & 443,449 & 6,889 & 3.13 \\
\hline $\begin{array}{l}\text { Otros } \\
\text { municipios } \\
\text { de Cortés }\end{array}$ & 16,603 & 417,579 & 40,865 & 475,047 & & \\
\hline $\begin{array}{l}\text { Otros } \\
\text { municipios } \\
\text { fuera de } \\
\text { Cortés }\end{array}$ & 13,504 & 7,855 & 4226,958 & 4248,317 & & \\
\hline Total & 436,560 & 430,556 & 4299,697 & 5166,813 & & \\
\hline
\end{tabular}

Fuente: Elaboración propia en base a datos de la matriz básica de migración reciente, MIALC-CELADE

En el período 2008-2013 muestra claramente como el atractivo migratorio reciente de San Pedro Sula se pierde, la migración neta es de $-12,333$ personas y una tasa de migración de -4.36 , indicando que el municipio recibe menos migrantes que los que envía a otros municipios, principalmente los cercanos (Cuadro $\mathrm{N}^{\circ} 10$ ).

Existe una pérdida de atracción migratoria de San Pedro Sula que se manifiesta en la migración reciente entre el período 1996-2001 y 2008-2013, cuando cambia la migración neta a negativa y que es producida por los intercambios que se producen hacia y desde este municipio y que está influenciado por los intercambios negativos con los municipios cercanos, incluso intuimos que continuará con la migración lejana (Gráfico N³).

Cuadro №10 San Pedro Sula: matriz de migración reciente con otros municipios del país agrupados en categorías de cercanía 2013-2008

\begin{tabular}{|c|c|c|c|c|c|c|}
\hline \multirow{2}{*}{$\begin{array}{l}\text { Zona de } \\
\text { residencia } \\
\text { al momento } \\
\text { del censo } \\
(2013)\end{array}$} & \multicolumn{3}{|c|}{$\begin{array}{l}\text { Zona de residencia cinco años } \\
\text { antes del censo (2008) }\end{array}$} & \multirow[b]{2}{*}{$\begin{array}{l}\text { Total } \\
\text { censo }\end{array}$} & \multirow{2}{*}{$\begin{array}{c}\text { Migración } \\
\text { neta (total } \\
\text { censo - } \\
\text { total cinco } \\
\text { años antes }\end{array}$} & \multirow{2}{*}{$\begin{array}{l}\text { Tasa de } \\
\text { migración } \\
\text { neta (por } \\
\text { mil) }\end{array}$} \\
\hline & $\begin{array}{l}\text { San Pedro } \\
\text { Sula }\end{array}$ & $\begin{array}{c}\text { Otros } \\
\text { municipios } \\
\text { de Cortés }\end{array}$ & $\begin{array}{c}\text { Otros } \\
\text { municipios } \\
\text { fuera de } \\
\text { Cortés }\end{array}$ & & & \\
\hline $\begin{array}{l}\text { San Pedro } \\
\text { Sula }\end{array}$ & 531,514 & 4,226 & 23,597 & 559,337 & $-12,333$ & -4.36 \\
\hline \begin{tabular}{|l|} 
Otros \\
municipios \\
de Cortés
\end{tabular} & 17,308 & 610,798 & 42,381 & 670,487 & & \\
\hline \begin{tabular}{|l} 
Otros \\
municipios \\
fuera de \\
Cortés
\end{tabular} & 22,848 & 211,298 & 5271,629 & 5505,775 & & \\
\hline Total & 571,670 & 826,322 & 5337,607 & 6735,599 & & \\
\hline
\end{tabular}

Fuente: Elaboración propia en base a datos de la matriz básica de migración reciente, de base censal 2013

\section{Gráfico $\mathbf{N}^{\circ} 3$ San Pedro Sula: migración cercana y lejana, 2001-1996 y 2013-2008}

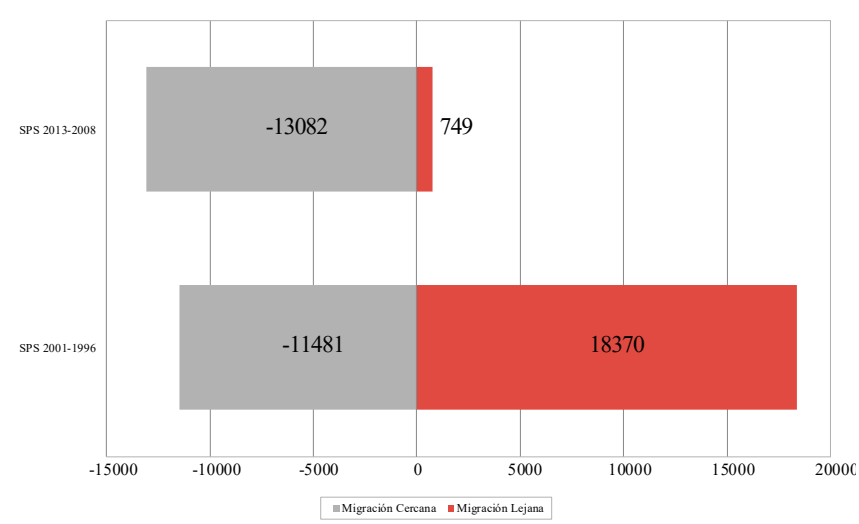

Fuente: Elaboración propia en base a datos de la matriz básica de migración reciente. 2001 y 2013.

\section{Conclusiones}

Los dos municipios en estudio mantienen su atractivo en la medición de migración de toda la vida, esto porque albergan las dos principales ciudades del país, una desde el ámbito político-administrativo y la otra por su carácter industrial, siendo las más pobladas y las que tienen los mejores indicadores de desarrollo por su concentración de recursos que en ella se generan.

La migración de toda la vida en estos municipios todavía muestra signos de atracción, ya que los flujos inmigratorios fueron mayores que los emigratorios en la medición que es acumulada hasta el año del recuento censal, en otras palabras es provocada por los flujos ocurridos desde hace mucho tiempo. 
En el caso de la migración reciente esta tendencia ha evolucionado hacia la reducción del número de municipios con los que se tienen saldos migratorios positivos, principalmente para San Pedro Sula donde se redujo de 240 a 115 en el período 2001-2013, en otras palabras, actualmente con el $57 \%$ de los municipios tiene migración neta negativa.

En la migración reciente (cinco años antes) los flujos mayores de mil personas en el 2013 para ambos municipios sólo hay quince eventos, para el Distrito Central sus orígenes son de San Pedro Sula, Choluteca, Danlí y Juticalpa, mientras los destinos específicos son para los municipios de San Pedro Sula y Danlí. En San Pedro Sula los migrantes recientes proceden del Distrito Central, Choloma, Santa Bárbara y La Ceiba, mientras desde este municipio sus destinos son para Villanueva, Choloma, La Lima, Distrito Central, San Manuel y Quimistán.

Con las matrices de migración interna reciente a nivel de DAME se deriva una matriz de migración cercana y lejana tomando en consideración el límite geográfico de la DAM, resultando que en la medición 2008-2013 para los municipios de estudio ocurre una pérdida de atracción migratoria reciente en ambos municipios, en mayor medida en San Pedro Sula, determinado por el intercambio cercano que resulta negativo y superior al lejano.

\section{Bibliografía}

- CEPAL (2017). MIALC, Migración Interna de América Latina y el Caribe, Base de datos, Santiago de Chile, CELADE-CEPAL.

- Fernández Fernández, H. A. (2016). Migración Interna y Mercado Laboral en San Pedro Sula, Cortés, 2006 y 2013. San Pedro Sula: MDD-VS-UNAH.

- Flores Fonseca, M. A. (2002). Origen de los Inmigantes Internos en Tegucigalpa. Tegucigalpa: IIES-UNAH.

- Flores Fonseca, Manuel (2005), Migración interna intermunicipal de Honduras, Tegucigalpa, Instituto de Investigaciones Económicas y Sociales (IIES), Universidad Nacional Autónoma de Honduras (UNAH).

- Flores Fonseca, M. A. (2010). Migración Interna en Cuatro Ciudades de Honduras. Revista Economía y Administración, Vol.1 No.2, 154-171, Tegicugalpa, IIES-UNAH.

- Flores Fonseca, M. A. (2017). Niveles, Tendencias, Orígenes y Destinos de la Migración Interna de Honduras, 1988-2013, Tegucigalpa, Honduras.
- Rodríguez Vignoli, Jorge (2004), “Migración interna en América Latina y El Caribe: estudio regional del período 1980-2000", serie Población y desarrollo, N 50 (LC/L.2059-P) Santiago de Chile, Comisión Económica para América Latina y el Caribe (CEPAL). Publicación de las Naciones Unidas, $\mathrm{N}^{\circ}$ de venta: S.04.II.G.3.

- Rodríguez, Jorge y Busso, Gustavo (2009). Migración Interna y Desarrollo en América Latina entre 1980 y 2005. Un estudio comparativo con perspectiva regional basado en siete países. (LC/G.2397-P), Santiago de Chile, Comisión Económica para América Latina y el Caribe (CEPAL). Publicación de las Naciones Unidas, Nº de venta: S.09.II.G.14.

- Sierra, L. (2016). Condiciones de Vida de la Población Inmigrante del Distrito Central, Honduras, año 2013. Población y Desarrollo Argonautas y Caminantes Vol.12, 8192. Tegucigalpa, UNAH. 